\title{
A timely harvest
}

\section{The public should be consulted on contentious research and development early enough for their opinions to influence the course of science and policy-making.}

\section{Pierre-Benoit Joly and Arie Rip}

Public engagement in emerging science and technology is thriving, particularly in the United Kingdom. Recent initiatives such as 'Nanodialogues', organized by the think-tank Demos, suggest that citizen juries, dialogue exercises and interactive public understanding projects can be fruitful for scientists and members of the public. Over two years, the Nanodialogues series allowed members of the public to join scientists in discussions on regulation, research funding, development and corporate innovation of nanotechnologies. Such enterprises may foster mutual understanding, but they can struggle to make a difference to research or to policy-making.

Governments and research institutions generally fail to respond to the outcomes of public engagement exercises, perhaps because the outcomes are often too late and too vague on concrete strategies to move forward. We've learnt that it is better to engage the public 'midstream', at a point in the research process when it is possible to incorporate their opinions into research orientation and policymaking.

The French National Institute of Agronomic Research (INRA) used such an approach to focus on research into and field trials of genetically modified vines. In 2001, INRA had to decide whether to run field trials of a genetically modified vine that is potentially resistant to a disease-causing virus. INRA's research director for plant sciences, Guy Riba, voiced the opinion of most researchers: "Surely scientists have a responsibility to carry out these experiments with a view to the future, even in the face of current public opposition?"

INRA met strong opposition to the trials because of the cultural significance of wine in France. A group of wine producers, including some prestigious châteaux, had signed a petition in June 2000 calling for a moratorium on the use of genetic modification techniques in wine production, and joined forces to create the non-governmental organization Terre et Vin du Monde (Land and Wine of the World).

In response, INRA asked a group of social scientists who specialize in science and technology studies to organize a public consultation, in which we took leading roles. Our goal was to produce a public report to be taken into account in decisionmaking at INRA.

Our working group comprised 14 people, including members of the public, wine growers and researchers. It had seven days of intensive discussions over a sixmonth period in 2002. The set of recommendations it produced was made freely

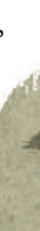

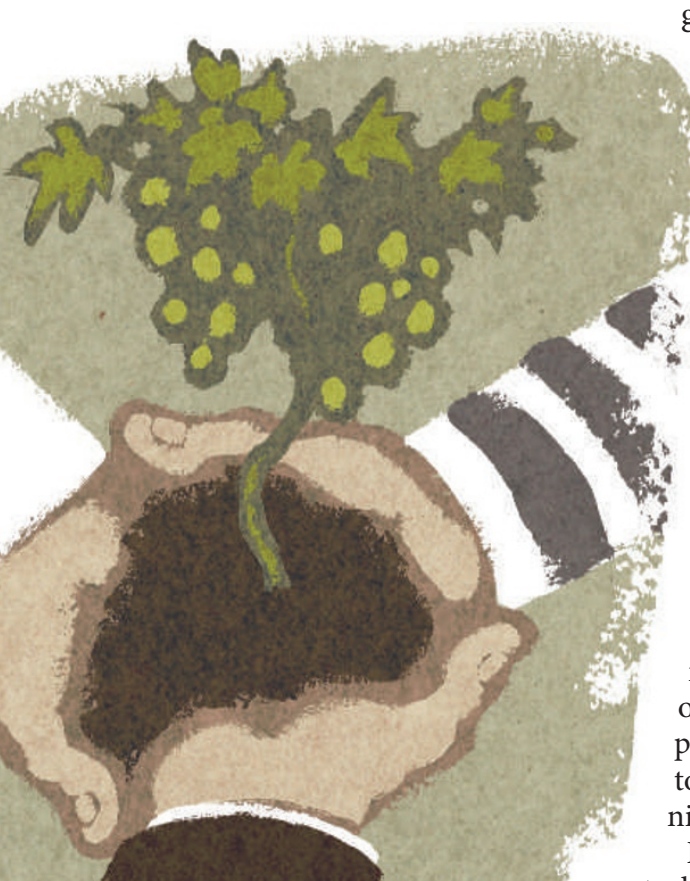

not for commercial purposes; that a local committee would be in charge of monitoring the experiment; and that INRA would commit to exploring alternative ways to fight viruses. Appropriately, it was not a smooth process, either during deliberation within the group, or in implementing the agreement.

Researchers at INRA criticized the public consultation process for its power to reduce the freedom of research. Nongovernmental organizations claimed that INRA was manipulating public opinion through the exercise. These tensions are an unavoidable part of the process.

Three important lessons emerged from the exercise. First, midstream engagement is not a recipe for wide social agreement and acceptance. Rather, it improves the robustness of decisions by taking into account the diversity of world views and interests. Second, it stimulates institutional learning. Third, the process can produce research and development options not previously considered. This is of particular value if directors of public research are truly committed to generating beneficial sociotechnical innovation.

Public consultations in science and technology should be undertaken at a point early enough in the development process when it is still feasible to change course. The nanotechnology world often refers to 'the lessons to be learned from genetic modification' - the main one is timely, considered public engagement. Pierre-Benoit Joly is director of research at INRA, 65 Boulevard de Brandebourg,

F-94205 Ivry, France, and director of the TSV (Social and Political Transformations related to Life Sciences) research unit. Arie Rip is emeritus professor of philosophy of science and technology at the University of Twente in Enschede, the Netherlands, and leads a programme on social and ethical aspects of nanotechnology.

For more essays and information see http://nature.com/ nature/focus/scipol/index.html. tive. It yielded some unexpected recommendations that could be worked into the decision-making process. Some of the participants opposed the field trial at all costs, but most supported it under strict conditions, including: that INRA guaranteed that the trials would be used only for research,

\section{Correction}

In the Essay 'Big lessons for a healthy future' (Nature 449, 791-792; 2007) the conversion of $€ 45.5$ billion should have read US\$93 billion, not million. 